\title{
CLCA for Assessing Environmental Impacts of Power Sector in the GHG Policy Context
}

\author{
Le Quyen Luu ${ }^{1,2}$, Sonia Longo ${ }^{1 *}$, Maurizio Cellura ${ }^{1}$, Eleonora Riva Sanseverino $^{1}$ \\ ${ }^{1}$ Università degli Studi di Palermo - Dipartimento di Ingegneria, Viale delle Scienze Ed.9, 90128, Palermo, Italy \\ ${ }^{2}$ Institute of Energy Science - Vietnam Academy of Science and Technology, 18 Hoang Quoc Viet, Cau Giay, Hanoi, Vietnam
}

Corresponding Author Email: sonia.longo@unipa.it

https://doi.org/10.18280/ti-ijes.642-416

Received: 16 March 2020

Accepted: 5 June 2020

\section{Keywords:}

CLCA, environmental impact, power sector, socio-economic interaction

\begin{abstract}
Purpose: Current greenhouse gas (GHG) policy aims at reducing emissions from power sector. However, there are some known trade-offs of GHG emission reductions, in terms of other types of environmental impacts and impacts on other economic sectors. Consequential life cycle assessment (CLCA) has been developed to assess the environmental impacts of the power sector in relation with changes in the policy and its indirect impacts on other economic sectors.

Methods: A systematic review of CLCA method is conducted in the power sector. CLCA studies since 2005 are reviewed in terms of obtained results and methodology to identify whether CLCA is a more suitable approach for assessing environmental impacts of power sector in the context of GHG policy intervention, compared to attributional life cycle assessment (ALCA).

Results and discussion: With CLCA the total environmental impacts/benefits of power system change when indirect impacts are accounted. The variations between the total environmental impacts quantified with CLCA and ALCA range widely from inconsiderable difference (less than $5 \%$ ) to $200 \%$, depending on the investigated product system. These variations originate from CLCA's modelling principles of expanding the system boundary and the inclusion of socio-economic interactions. With the expansion of system boundary, CLCA covers affected products and accounts for their relevant environmental impacts, which makes the obtained results comprehensively quantified. At the same time, the inclusion of socio-economic interactions in CLCA improves its capability of identifying the connections between environmental impacts and social-economic changes such as economic growth and consumer behaviours.
\end{abstract}

\section{INTRODUCTION}

By 2018, the greenhouse gas (GHG) emissions with land use, land use change and forestation of Annex I countries was $14.91 \mathrm{GtCO}_{2} \mathrm{e}[1]$. The emissions of energy sector accounted for $90 \%$ of the total emissions $\left(13.47 \mathrm{GtCO}_{2} \mathrm{e}\right)$ [1]. The power and heat generation sector, in particular, contributed to 9.76 $\mathrm{GtCO}_{2} \mathrm{e}$ in 2017 and increased 2.5\% in 2018 [2]. Although there was a small reduction in emission intensity of $1.3 \%$ as a result of the application of renewable energy and energy efficiency technologies, the growing demand of power was the principal cause of the increasing total GHG emissions [2].

The trend of current GHG policy aims at decarbonisation, sustainable environment, economic prosperity, and social equity [3]. It requires the deep decarbonisation of the economies, in which the energy systems as well as other emission intensive sectors need to transform into zero emission ones, while ensuring the economic development and meeting the need of population growth [4]. The Deep Decarbonisation Pathway Project countries, which contribute to $74 \%$ of global energy related GHG emissions, set the objective that by 2050 their GHG emissions of energy sector will be reduced of $46-56 \%$ compared to 2010 level, while maintaining the average gross domestic product (GDP) growth of $3.1 \%$ and the population growth of $17 \%$ annually [4].
During the decarbonisation process there are trade-offs on other environmental impacts and other economic sectors. In power sector, for example, bio-power is believed to cause less GHG emissions compared to coal thermal power, but it may increase the eutrophication and acidification due to the energy crop plantation [5]. In such case, the GHG emissions of power sector will reduce, but other negative environmental impacts from agriculture sector will increase.

Life cycle assessment (LCA) quantifies the life cycle environmental impacts of a product system, covering all stages from raw material extraction and processing, product and/or service manufacturing, use and disposal, and transportation [6]. The comprehensiveness makes LCA a particularly effective mechanism for quantifying different environmental impacts originating from the product's life cycle including indirect impacts.

There are two types of LCA approaches, namely attributional LCA (ALCA) and consequential LCA (CLCA). In the ALCA approach, inputs and outputs of a product system are attributed to its functional unit by linking the unit processes of the system while defining a physical boundary and isolating it from other systems [7]. Meanwhile, consequential LCA (CLCA) has been developed to quantify the environmental impacts of a product system in relation with changes within its life cycle [7]. 
Due to the principal differences between the two approaches ALCA and CLCA, it is expected that the obtained results with the application of each approach will be different. This paper reviews CLCA studies in power sector in terms of the obtained results and methodology in order to consider the capability of CLCA approach in modelling the life cycle environmental impacts of the power system and power generation/storage technologies in the context of GHG policy.

\section{METHODOLOGY}

The review followed Glasziou's approach which guided on 5 step approach of conducting a systematic review, including: Develop research questions; Finding relevant studies; Appraising quality and extracting data; Synthesizing and Interpreting [8]. The literature search was conducted on Web of Science with the terms of "consequential life cycle assessment AND energy sector" in January and February, 2020. Although this review paper focused on power sector, the term of "energy" has been selected instead of "power" as it was assumed that there were studies on energy sector which included power, heat, fossil fuels, and biofuel, etc. Only papers with illustrated case study were included. Reviews and papers proposing framework/ approach were excluded from this review, but they were referred in this paper for discussion purposes. The initial search gave out 221 CLCA papers being published from 2005 to the present. These papers were primarily screened through the titles and abstracts to exclude ones relevant to food/nutrient energy and ones that assessing energy as a medium during the production line, instead of the product system.

At the end of the primary screening there were 97 papers on three topics: energy, bioenergy and power. Papers on "energy" topic are composed of those studying fossil fuels or studying both power and heat simultaneously, while papers on "power" topic solely concentrated on different types of power, i.e. coal, natural gas thermal power, nuclear power, hydropower, renewable power, and fossil fuel based power with carbon capture and storage (CCS).

In the secondary screening, papers on "bioenergy" topic were removed and papers on "energy" topic were skimmed and identified whether the papers included power as one of the product systems, or used power as the only input during the product system useful life. If yes, they were categorised into 'power' topic. The secondary screening aimed at avoiding any missing of papers that studied several types of energy including power and electric vehicles (EV) which have recently entered as the power system for regulation purposes through Vehicle To Grid (V2G) initiatives. Results of the secondary screening were 31 papers of CLCA on power sector, which were analysed towards the two aspects of CLCA methodology and the obtained results, including the expansion of system boundary, the inclusion of socio-economic interactions, and the ability to model indirect environmental impacts.

\subsection{The notion of CLCA}

There was a consensus on the causal relationship of CLCA. Most authors pointed out two distinguished features of CLCA: (1) changes in the environmentally physical flows and (2) as consequences of changes in the life cycle of the product system [9-12]. These changes (effect) occur in the technological (product) system, while the cause of changes originates from different decisions. These decisions occur during the life cycle of the product system. There is no limitation on types of decisions, and it may extend to decisions on technological improvement of a company, or governmental policy decisions on subsidy for a product, or to limit the consumption of a product.

The common principle of causal relationship of CLCA was handled under the view of economic interactions. Some authors clarified CLCA as an approach to account environmental impacts when there was an increase or decrease in demand on the product system $[13,14]$. In other words, these authors made a connection of consequential relationship of LCA due to economic changes.

Table 1. Comparison between ALCA and CLCA $[12,16]$

\begin{tabular}{|c|c|c|}
\hline Features & ALCA & CLCA \\
\hline Goal & $\begin{array}{l}\text { To assess potential environmental impacts, including inputs and } \\
\text { outputs of a product system per its functional unit over its life } \\
\text { cycle. }\end{array}$ & $\begin{array}{l}\text { To assess potential environmental impacts of a product } \\
\text { system in relation with changes per its functional unit over } \\
\text { its life cycle. }\end{array}$ \\
\hline \multirow[t]{4}{*}{ Application } & Answer for question "How things are?" & Answer for question "What if?" \\
\hline & Hotspot identification or product comparison. & Reflection of causality. \\
\hline & ALCA is relevant when no specific decision is at hand for & Used for decision making. \\
\hline & $\begin{array}{l}\text { increasing the understanding of the causal relations within the } \\
\text { product chain, and between this chain and the surrounding } \\
\text { technological systems. }\end{array}$ & $\begin{array}{l}\text { CLCA is relevant when rational decision making is needed. } \\
\text { This process requires information about the consequences } \\
\text { of the decision. }\end{array}$ \\
\hline $\begin{array}{l}\text { Product } \\
\text { system }\end{array}$ & Normally there is one product system per a LCA. & $\begin{array}{l}\text { The product systems are broadened to include several } \\
\text { similar or relevant products. }\end{array}$ \\
\hline $\begin{array}{l}\text { System } \\
\text { boundary }\end{array}$ & $\begin{array}{l}\text { Over the product system's whole life cycle (from cradle to } \\
\text { grave), or a part of its life cycle (from cradle to gate, from gate } \\
\text { to gate, from gate to grave). }\end{array}$ & $\begin{array}{l}\text { The system boundary is broadened to include unit processes } \\
\text { and products as consequences of change/ intervention. }\end{array}$ \\
\hline $\begin{array}{l}\text { Functional } \\
\text { unit }\end{array}$ & 1 unit of function of product system. & $\begin{array}{l}1 \text { unit of function of marginal product system. } \\
\text { Functional unit of the whole system would consist of } \\
\text { multiple functions, including the main system and those } \\
\text { added by the processes included in the boundaries. }\end{array}$ \\
\hline Allocation & $\begin{array}{l}\text { The impacts are ascribed for main product and co-products } \\
\text { based on economic value (price) or physical value (volume, } \\
\text { mass). }\end{array}$ & $\begin{array}{l}\text { System boundary is broadened to include main product and } \\
\text { co-products, so there is no need of allocation. }\end{array}$ \\
\hline
\end{tabular}


To make a clear distinction between CLCA and ALCA, several authors conducted systematic reviews on CLCA methodology $[12,13,15]$. Other authors reviewed different models for life cycle analysis and focused on the outstanding features of CLCA in capturing environmental impacts of a product system under economic interactions [16-18]. These reviews indicated that ALCA and CLCA were vastly different in terms of application scale for small/large economic sector, (increased) number of products, (expansion of) system boundary. The differences between CLCA and ALCA are summarized in Table 1.

\subsection{Direct and indirect life cycle environmental impacts}

The environmental impacts of power sector have been widely studied for its whole life cycle. They include not only direct impacts arising during the generation of power, but also the indirect ones. The indirect impacts may either lie in the intermediate products that contribute to the power's life cycle, e.g. land use impacts for the development of bio-electricity, impacts from equipment and power infrastructure, impacts from background processes such as primary energy, fuel extraction for power generation; or may be originated from the affected products which are related to the power in some ways, e.g. impacts from increasing battery integration into the power grid on other types of power technologies such as wind power, solar power or thermal power in the generation mix, impacts from increasing or decreasing demand on products of power intensive industries such as metal manufacturing and food processing on power grid structure and capacity.

While the former type of indirect impacts, e.g. impacts from intermediate products, can be quantified with ALCA, the latter types of indirect impacts, e.g. impacts from affected products, are deem to be quantified with CLCA. In this paper, the term "indirect environmental impacts" is used to denote the latter type of impacts which originates as consequence of changes in the product system. These changes include different types of changes in the socio-economy, such as change in the governmental policy decision, or change in the market demand of the studied product system or any relevant products and coproducts.

\section{RESULTS AND DISCUSSION}

\subsection{System boundary}

One of distinguished features of CLCA is the expansion of system boundary, i.e. the inclusion of unit processes [16] and different products and co-products [19] to the extent of the expected changes. At the early time of CLCA development, Weidema proposed an approach, in which the expansion of system boundary was conducted under the ceteris paribus (other things being equal) assumption [20]. The author suggested an approach to identify affected products in five steps [20, 21], including:

(1) What scale and time horizon does the study apply to?

(2) Does the change only affect specific processes or a market?

(3) What is the trend in the volume of the affected market?

(4) Is there potential to provide an increase or reduction in supply and demand?

(5) Is the technology the most/least preferred?
This stepwise approach clarified the links between the product systems and unit processes through intermediate products (ALCA) as well as identified the consequences on supply and demand of products and co-products (CLCA) [21]. Due to the limitation of data availability at this time, it was suggested to assume that the scale of change was small [21]. Therefore, the suggestion of applying the ceteris paribus assumption when expanding the system boundary is reasonable.

Frischknecht and Stucki proposed a methodology framework in which depending on the changing agent, its potential effect and the size of studied product systems, different modelling techniques will be applied [22]. Specifically, if the changing agent has small potential consequences, for example individual decision of buying lamps of company $\mathrm{X}$, the ceteris paribus assumption should be applied. Meanwhile, if the changing agent has large potential consequences, for example, policy to encourage the consumption of five-star energy rating lamps in country $\mathrm{Y}$, the mutatis mutandis ("the necessary changes being made") assumption should be applied [22]

In the former example, the decision of whether to buy a specific product is applicable at a small scale, and the consequence of that decision is limited in physical change, i.e. change of quantity of environmental impacts without changes in economic systems. Meanwhile, in the latter example, the decision of introducing a policy to encourage a product or technology will induce changes in other relevant economic sectors. In order to accurately quantify the impact, it is necessary to expand the system boundary. The authors concluded that CLCA, therefore, would be relevant for quantifying impacts of changes due to governmental policy or strategic international organization decision in which the investigated object has a relatively large economic size [22].

It is suggested that if the relative economic size of studied product system is small to medium, i.e. accounting for less than $0.1 \%$ or from $0.1 \%$ to $1 \%$ of the market share, respectively, the ALCA approach should be applied. In contrast, if the market share of the studied product system is larger than 1\%, the CLCA approach should be applied [22]. Although the criteria are not adequately convincing, they are the initial effort of how to deal with system expansion in CLCA, based on quantitative economic value [23-27].

Among reviewed CLCA papers in power sector, some authors made it very clear on the inclusion of extended unit processes; other authors did not clearly identify the unit processes of a product system's life cycle [28-35].

The system boundary is extended to at least two products in all reviewed studies. Moreover, it is even extended to several relevant economic sectors. The investigated products and economic sectors of some reviewed CLCA papers are specified in Table 2 .

All of the reviewed studies expanded the product system boundary, by either increasing unit processes, or including relevant products and co-products [36, 37]. This approach helps to identify products or technologies being affected as consequences of changes. However, the ways how these affected products and co-products being treated were different. Some authors treated the affected product under ceteris paribus assumption. In this case, they simulated the consequences in form of physical change, or the affected products can be substituted by other similar ones. These physical changes were modelled through quantifying energy flows, for example in Jones et al.'s study which used net 
energy analysis [38]. The affected products were treated by substitution and cut-off, for example, marginal electricity production was replaced by power from waste incineration and material recycling as in Eriksson et al.'s study [23].

Table 2. Product systems and affected products of some reviewed papers

\begin{tabular}{|c|c|}
\hline Studies & Investigated product systems \\
\hline $\begin{array}{c}\text { Pizarro- } \\
\text { Alonso et al. } \\
{[24]}\end{array}$ & $\begin{array}{l}\text { Waste management approaches, } \\
\text { waste to energy }\end{array}$ \\
\hline $\begin{array}{l}\text { Moora and } \\
\text { Lahtvee } \\
{[25]}\end{array}$ & Waste management approaches \\
\hline $\begin{array}{l}\text { Pehnt et al. } \\
\text { [26] }\end{array}$ & Wind power \\
\hline $\begin{array}{l}\text { Blanco et al. } \\
\text { [27] }\end{array}$ & Power to methane \\
\hline $\begin{array}{l}\text { Mathiesen } \\
\text { et al. [28] }\end{array}$ & Power and heat from waste \\
\hline $\begin{array}{c}\text { Lund et al. } \\
\text { [29] }\end{array}$ & Power \\
\hline $\begin{array}{l}\text { Igos et al. } \\
{[30]}\end{array}$ & $\begin{array}{l}\text { Six energy final products } \\
\text { including liquid fuels, fuels, } \\
\text { coke, refined petroleum, } \\
\text { electricity, products of mining } \\
\text { and quarrying of energy, and gas, } \\
\text { steam and hot water }\end{array}$ \\
\hline $\begin{array}{l}\text { Gibon et al. } \\
\text { [31] }\end{array}$ & $\begin{array}{l}17 \text { energy technologies including } \\
\text { bioenergy, coal, hydropower, } \\
\text { natural gas, natural gas, } \\
\text { concentrating solar power, } \\
\text { nuclear power, solar } \\
\text { photovoltaics (solar PV), wind } \\
\text { power and CCS }\end{array}$ \\
\hline $\begin{array}{l}\text { McDowall } \\
\text { et al. [32] }\end{array}$ & $\begin{array}{l}18 \text { power technologies from } \\
\text { wind, solar PV, coal, combined } \\
\text { cycle gas turbine, conventional } \\
\text { gas, nuclear, hydro, oil, biomass } \\
\text { and waste }\end{array}$ \\
\hline
\end{tabular}

Raugei et al. Solar PV power

[33]

Algunaibet The US power system with power et al. [34] from coal, natural gas, nuclear, hydropower, biomass, geothermal, solar PV, solar thermal, wind, bioenergy and CCS

Vandepaer Two types of batteries

et al. [35]

Dandres et The European (EU) electricity al. [36] and heat
Affected products

Different types of power such as coal, natural gas, biomass, wind, solar, ocean, geothermal and nuclear power

Different types of power

Thermal power such as power from coal, lignite and gas

The EU power system

Energy from coal, oil natural gas and biomass Energy from wind, coal and natural gas

Different types of UK ongrid power such as wind, nuclear, coal, gas and biomass power

On-grid power
Coverage of economic sectors

Two sectors of waste management and power generation

The whole economic system of energy supply and demand sectors, including power, heat, industry, transport, and supply (supply); and commercial, residential, industry, mobility and agriculture (demand)

Six economic sectors of Luxembourg: Agriculture, Construction, Industry, Electricity production and distribution, Transport, and Other industries
The comprehensive energy supply and demand sectors of fuel provision sectors, power generation sectors (Agriculture, Forestry, Coal, Leather, Wood, Pulp \& Paper, Printing \& Media, Coke, Nuclear fuel, Chemicals, Rubber \& Plastic products, Other non-metallic mineral products, Fabricated metal products) and power consumption sectors (Agriculture, Pulp \& Paper, Chemicals, Non-Metallic minerals and Other industry)
20 globally economic sectors: Grains and crops; Livestock and meat products; Processed food; Water; Textiles and clothing; Light manufacturing; Heavy manufacturing; Utilities and construction; Transport and communication; Other services; Coal and lignite extraction; Gas extraction; Oil and peat extraction; Minerals; Fuels; Gas, steam and hot water; Electricity; Forestry; and Pulp, paper, publishing and Wood products 
The reviewed papers that applied the ceteris paribus assumption were conducted at the early time of CLCA development, when the methodology is emerging. At this time, most of authors focused on the causal relations of change in the product system and affected product, rather than socioeconomic relations between them. These "claimed to be CLCA" studies should be regarded as using consequential concept, in which they applied consequential approach by mentioning the causal relationship, and its consequences on the environmental impacts of the product system without considering it under the socio-economic interaction.

Another approach to identify affected products is considering them under the mutatis mutandis assumption. The changes in the affected products were determined by reviewing literatures, being based on stakeholders' participations, and running economic models. In power sector, Mathiesen et al. identified marginal energy technologies by looking at publications on historical and future energy system and existing CLCAs [28]; Dandres et al. took the business-asusual (BAU) and future renewable technology mixes from peer-reviewed publications [36]; and Gibon et al. determined the existing power generation mixes and the regional technology performance from International Energy Agency reports and the New Energy Externalities Development for Sustainability project, and identified changes in the future power system structure and fuel consumption due to the increased adoption of clean power technology based on experts' opinions [31].

Several authors used economic models to determine marginal technologies, for example, EU Electricity Market Model (E2M2) [26], EnergyPLAN [28, 29], MARKAL [39], ETEM [30], Network Impact Assessment Model [40], TIMES (ETM-UCL) [32], Unit commitment model [33], Balmorel [24], Swiss TIMES Energy Model (STEM) [35] and JRC-EUTIMES [27].

The system boundary of CLCA, as a result, goes beyond the physical boundary to extend to the market boundary. The physical boundary of the product system, as being widely accepted, covers a spatial, geographical dimension, for example, a region or country during four stages of a product life cycle: raw material extraction, manufacturing, using and end of life. Meanwhile, the market boundary covers a market area of several industries and economic sectors. It also considers market effects, for example, change in electricity price and production cost, and sometimes even consider rebound effect and feedback mechanism. With the expansion to market boundary, CLCA clearly covers more products compared to the traditional one. Therefore, CLCA will more accurately analyse environmental impacts, either negative or positive, of a product system in the context of policy intervention, compared to ALCA.

\subsection{Socio-economic interactions}

According to Weidema, Earles and Halog, Zamagni et al., being different from ALCA, which focuses on the physical inflows and outflows of environmental impacts of a product system, CLCA considers the interactions of economic sectors on the product systems and the relevant environmental impacts $[13,16,19]$. These authors agreed on the economic interactions in the CLCA through the inclusion of market mechanism or economic-based causal relationship.

The most common way to model the economic relationship is combining an economic modelling tool and LCA. The applicable economic models are either partial equilibrium (PE), computerized general equilibrium (CGE), input output (IO) or dynamic models (DM), which are also common in CLCA studies in energy sector in general [41]. Two thirds of reviewed papers applied economic models to simulate the economic interactions between power sector and other sectors. The pathway for integrating these models into CLCA is running the models to obtain scenarios with changes in affected sectors and identify affected products/ technologies. These scenarios and data on affected products/ technologies will be used for running CLCA.

Table 3. Applicable tools in reviewed studies

\begin{tabular}{|c|c|c|c|c|c|c|}
\hline Study & $\mathrm{PE}$ & CGE & IO & $\mathrm{DM}$ & LR & Expert based \\
\hline Dandres et al. [36] & & $\mathrm{Y}$ & & & $\mathrm{Y}$ & \\
\hline Eriksson et al. [23] & $\mathrm{Y}$ & & & & & \\
\hline Pizarro-Alonso et al. [24] & $\mathrm{Y}$ & & & & & \\
\hline Pehnt et al. [26] & $\mathrm{Y}$ & & & & & \\
\hline Blanco et al. [27] & $\mathrm{Y}$ & & & & & \\
\hline Mathiesen et al. [28] & & & $\mathrm{Y}$ & & $\mathrm{Y}$ & \\
\hline Lund et al. [29] & & & $\mathrm{Y}$ & & & \\
\hline Igos et al. [30] & $\mathrm{Y}$ & $\mathrm{Y}$ & & & & \\
\hline Gibon et al. [31] & & & $\mathrm{Y}$ & & Y & $\mathrm{Y}$ \\
\hline McDowall et al. [32] & $\mathrm{Y}$ & & $\mathrm{Y}$ & & & \\
\hline Raugei et al. [33] & $\mathrm{Y}$ & & & & & \\
\hline Algunaibet et al. [34] & $\mathrm{Y}$ & & & & & \\
\hline Vandepaer et al. [35] & $\mathrm{Y}$ & & & & $\mathrm{Y}$ & $\mathrm{Y}$ \\
\hline Elzein et al. [37] & $\mathrm{Y}$ & & & & & \\
\hline Choi et al. [39] & $\mathrm{Y}$ & & & & & \\
\hline Jones and Gilbert [40] & & & $\mathrm{Y}$ & & & \\
\hline Florent and Enrico [43] & & & & $\mathrm{Y}$ & & \\
\hline Onat et al. [44] & & & & $\mathrm{Y}$ & & \\
\hline Hammond and O'Grady [45] & & Not clear & & & $\mathrm{Y}$ & Y \\
\hline
\end{tabular}

$\mathrm{Y}=\mathrm{Yes}$

Hammond and O'Grady presented three pathways to a low carbon power sector of UK by 2050, through coal phase out, and technological innovations in CCS, and combined heat and power. These pathways were developed through Stakeholders workshop; Quantitative research; and Interdisciplinary workshop. The authors mentioned of applying economic models and interdisciplinary assessment in "quantitative research" step; however, it is not clear which models have been used [45]. 
Among reviewed papers, the numbers of studies using PE model are much larger than those using the two latter models, at 11 studies compare to two studies applying CGE and five studies applying IO and two studies applying DM. More interestingly, it is common that the studies apply several types of economic models, for example $\mathrm{PE}$ in combination with CGE, PE in combination with IO. The applications of PE, CGE and IO have the advantage of available data and (energy) economic models. Meanwhile, The DM is limited in terms of availability of data and modelling tools, but works well with socio-economic data [41]. Table 3 presents the reviewed CLCA case studies and their applicable models.

The good point of integrating economic models, e.g. IO/ $\mathrm{PE} / \mathrm{GE}$ into LCA, is that they provide details of the economic causal relationship [42]. Economic models work with one or several economic sectors, therefore, they either provide a specific view of one economic sector, or a comprehensive view of the product system in relations with the economy. This will help to clearly identify the hot spot economic sectors that contribute most to the impacts.

The economic model based CLCA accurately tracks the links between environmental impacts and economic indicators. Dandres et al. applied CGE model to predict global economic perturbation potentially caused by two different European energy policies, and CLCA to quantify environmental impacts due to these policies. It was identified that, among economic sectors, the most impacted sector was coal extraction and power generation. Consequently, it contributes to most of the difference in the environmental impacts across the two scenarios. Moreover, the authors pointed out that the most sensitive causal relation lied in economic revolution or the change in the GDP, rather than the change in the demand [36]. Similarly, Igos et al. applied PE and GE models to evaluate the economic impacts of policy decisions on energy commodity demand in Luxembourg by 2030 and identify least cost technologies to meet that energy demand. The authors identified that the contribution of other economic sectors, except for energy sector, are quite similar across studied scenarios. Moreover, most of the environmental impacts originates from imported commodities [30].

Apart from economic causal relationship, CLCA also covers the social interrelations among the product system. In this case, the original changes are not limited in the decrease or increase of consumption and production which are quantitative, but also include changes in social indicators. This is mostly conducted with the application of DM such as system dynamics and agent based modelling.

CLCA based on system dynamics was applied to model sustainability impacts of three alternative vehicles including internal hybrid, plug-in hybrid and battery EV by 2050 and compared them with internal combustion vehicle [44]. The increase in the number of EVs being used caused environmental, economic and social impacts on carbon dioxide emissions, particulate matter formation, photochemical oxidant formation, vehicle ownership cost, contribution to GDP, employment generation, and the human health impacts. With CLCA approach, it was identified that EVs were expected to be the best alternative in long-term for reducing human health impacts and air pollution from transportation. Meanwhile the result based on average value indicated that plug-in hybrid vehicles had the largest potential GHG emission reductions [44].

Florent and Enrico combined agent based modelling and CLCA to model changes in vehicle private use in Luxembourg in relation with environmental impacts of battery EVs, plug-in hybrid EVs by 2020, and compared them with gasoline internal combustion vehicles and diesel internal combustion vehicles [43]. Different mobility policies cause changes on characteristics and number of travels, charging patterns and auxiliary use, consequently decrease global warming, fossil depletion, acidification, ozone depletion and photochemical ozone formation; and increase in metal depletion, ionizing radiations, marine eutrophication and particulate matter formation [43].

Recently, Frischknecht et al. [46] has reviewed papers of the 62nd LCA forum, and indicated that CLCA goes beyond the marginal mixed and avoided burdens. It involves causal modelling, which not only includes economic relationship but also social responsibility [46]. Although the social responsibility referred by Weidema concerned on the consequences of a company's action, it could be extended to the context of governmental policy intervention. An example is the impact on social wellbeing and rate of employment/unemployment, specifically the decreased labour in coal mining industry and the increased labour in solar PV panel manufacturing, due to the policy on renewable portfolio standard. In this case, the impacts of policy intervention would be larger than those of a company decision.

Among the reviewed papers there were only two case studies covering the social aspects or social relationship of the power system. These studies either simulated the social agents and their impacts on the product system [43], or simulated the socio-economic interactions of the product system over its life cycle [44].

Although there were not many CLCA studies on the power sector considering the social interactions at present, with the call for social inclusion in LCA community and the consequential impacts of increasing the integration of renewable energy sources into the power system it is expected that there will be more need of CLCA methodology to work with socio-economic indicators in analysing and assessing impacts of power system in the context of GHG policy intervention.

\subsection{Indirect environmental impacts}

CLCA is successful in simulating the indirect environmental impacts. When the indirect impacts are included, the total environmental impacts when being assessed with CLCA are either larger or smaller than those being assessed with ALCA. This was observed in several case studies that reported both direct and indirect environmental impacts results such as Pehnt et al., Dandres et al., Igos et al., Frischknecht and Stucki, Raugei et al., Vandepaer et al., Blanco et al. and McDowall et al. [22, 26, 27, 30, 32, 33, 35, 36] (see Table 4).

Pehnt et al. studied the increase of off-shore wind power in Germany and its GHG emission reduction. The increased offshore wind power substituted for thermal power from coal, lignite and gas, causing change in the power mix, operation of power system, expansion and reinforcement of the grid. The study indicated that in the low and high carbon certificate price scenarios, respectively, the specific carbon reductions per $\mathrm{kWh}$ offshore electricity in the year 2020 amount to 914 and $646 \mathrm{gCO}_{2} \mathrm{e}$, thanks to the substitution of thermal power [26]. The inclusion of the offshore wind power into the power system also affected the operation of thermal power plants and caused the loss in its operational efficiency, as a consequence, 
increased the GHG emissions of wind power, up to 70 and 18 $\mathrm{gCO}_{2} \mathrm{e}$ per $\mathrm{kWh}$ of off-shore wind power. The emission from wind induced grid extension is $22 \mathrm{gCO}_{2} \mathrm{e}$ per $\mathrm{kWh}$. When the emissions from all processes, including construction, operation and disposal of the wind energy park, wind- influenced grid expansion, carbon reductions due to thermal power substitution and GHG emissions from altered power plant operation were added up, the total net carbon reduction is $822 \mathrm{gCO}_{2} \mathrm{e}$ per $\mathrm{kWh}$ and at $606 \mathrm{gCO}_{2} \mathrm{e}$ per $\mathrm{kWh}[26]$.

Table 4. Direct and indirect environmental impacts of some reviewed CLCA papers

\begin{tabular}{|c|c|c|c|c|c|}
\hline Studies & Product system & Environmental impacts/ benefits & $\begin{array}{l}\text { Direct impacts } \\
\text { only }\end{array}$ & $\begin{array}{l}\text { Indirect impacts } \\
\text { included }\end{array}$ & Variation \\
\hline Pehnt et al. [26] & Wind power & GHG emission reductions (gCO2e/kWh) & $914 \sim 646$ & $822 \sim 606$ & $\begin{array}{l}-10.1 \% \sim \\
-6.2 \%\end{array}$ \\
\hline Dandres et al. [36] & $\begin{array}{l}\text { Electricity and } \\
\text { heat }\end{array}$ & Environmental impacts & & & $5.5 \%$ \\
\hline Igos et al. [30] & $\begin{array}{l}\text { Energy (including } \\
\text { power) }\end{array}$ & Human health, ecosystem and resources & & & $50.0 \%$ \\
\hline Frischknecht and & Power system & GHG emissions $(\mathrm{gCO} 2 \mathrm{e} / \mathrm{kWh})$ & 98 & 225 & $129.6 \%$ \\
\hline Stucki [22] & (French) & High radioactive waste $(\mathrm{mm} 3 / \mathrm{kWh})$ & 11 & 3,8 & $-65.5 \%$ \\
\hline & Power system & GHG emissions (gCO2e/kWh) & 554 & 473 & $-14.6 \%$ \\
\hline & $(\mathrm{EU})$ & High radioactive waste $(\mathrm{mm} 3 / \mathrm{kWh})$ & 3.5 & 3.4 & $-2.9 \%$ \\
\hline Raugei et al. [33] & Solar PV & GHG emissions & \multirow{4}{*}{\multicolumn{2}{|c|}{ no number was provided }} & $\pm 2 \%$ \\
\hline Vandepaer et al. [35] & Battery & 16 environmental benefits & & & \\
\hline \multirow[t]{2}{*}{ Blanco et al. [27] } & $\begin{array}{l}\text { Energy (including } \\
\text { power) }\end{array}$ & $\begin{array}{l}\text { GHG emissions ( } 85 \% \text { emission reduction } \\
\text { target policy) }\end{array}$ & & & $50 \%$ \\
\hline & & $\begin{array}{c}\text { GHG emissions ( } 90 \% \text { emission reduction } \\
\text { target policy) }\end{array}$ & & & $200 \%$ \\
\hline McDowall et al. [32] & Power sector & GHG emissions & & & $10 \%$ \\
\hline
\end{tabular}

Dandres et al. assessed the environmental impacts of EU electricity and heat generation in two EU energy policies, namely baseline and bioenergy, in consideration with and without global economic development. The quantified impacts included direct impacts of increased energy generation and indirect impacts due to change global economic activities served for increased energy generation in the EU. It was indicated that potential indirect impacts were higher than direct impacts, with impacts occurring inside the EU border only accounted for $5.5 \%$ of the total global potential impacts. Interestingly, indirect impacts of increased energy in bioenergy policy were considerably higher than those in baseline policy [36]. In other words, bioenergy policy which harnesses more renewable energy is regarded as being cleaner compared to baseline policy, in fact causes more environmental impacts due to its indirect consequences on global economic activities.

Igos et al. assessed the impacts on human health, ecosystem and resources of two energy policies: BAU and GHG. The environmental impacts included direct impacts from energy related processes (energy production: gate to gate contribution of energy technology and energy import: cradle to gate contribution of the imported fuels and electricity processes to the final impact) as well as indirect impacts (contribution of changes in other economic sectors and imports). The contribution of indirect impacts was up to $50 \%$ in all three impact categories. The environmental impacts in GHG policy were $2-3 \%$ lower than those in BAU policy. This difference mainly and directly came from energy sector. The contribution of other sectors to the difference of two policies environmental impacts was less than $0.1 \%$ [30].

Frischknecht and Stucki used attributional and consequential (decisional) life cycle inventories to quantify the environmental impacts of French and EU electricity supply [22]. The attributional life cycle inventory was taken from Ecoinvent database and the consequential life cycle inventory was based on EurElectric, other energy publications and expert opinions. The authors identified that there was a difference between the obtained results. In the French electricity supply mix, the GHG emissions rise from $98 \mathrm{gCO}_{2} \mathrm{e}$ per $\mathrm{kWh}$ with ALCA to $225 \mathrm{gCO}_{2} \mathrm{e}$ per $\mathrm{kWh}$ with CLCA. The volumes of high radioactive waste generated is 11 and $3.8 \mathrm{~mm}^{3}$ per $\mathrm{kWh}$, respectively [22]. Similarly, in the EU attributional and decisional electricity supply mix caused GHG emissions of 554 and $473 \mathrm{gCO}_{2} \mathrm{e}$ per $\mathrm{kWh}$ and generated high radioactive waste of 3.5 and $3.4 \mathrm{~mm}^{3}$ per $\mathrm{kWh}$, respectively [22].

Raugei et al. conducted a CLCA on increased uptake of solar PV on UK grid. The increase of solar PV capacity impacted the generation mix as well as the grid development, and consequently global warming potential of solar PV [34]. The authors identified that there was a small difference in the GHG emissions from the increased solar PV deployment, which originated from background stages of solar PV and changes in the generation mix [33]. Consequently, any change in the solar PV deployment had no considerable additional emissions of the UK on-grid power [33].

Vandepaer et al. quantified the environmental impacts of inclusion of battery into the Swiss power system by 2030. In the current policy scenario, the inclusion of battery caused the displaced electricity mix which was dominated by natural gas combined cycle units [35]. The inclusion of batteries generates environmental benefits in 12 of the 16 impact categories, including climate change, ozone depletion, particulate matter, ionizing radiation, photochemical ozone formation, acidification, terrestrial eutrophication, freshwater eutrophication, marine eutrophication, land use and water resource depletion. In low carbon scenario, marginal electricity generation being displaced due to the inclusion of batteries mostly comes from geothermal and hydropower which already have reduced environmental impacts. Therefore, the environmental benefits due to inclusion of battery reduce compared to those of current policy scenario [35].

Blanco et al. conducted an ex-post LCA analysis of results from JRC - EU - TIMES and estimated the environmental impact indicators across 18 sectors in scenarios that achieved $80-95 \%$ GHG emission reductions by 2050 in EU28+ 
countries. The results showed that the indirect $\mathrm{CO}_{2}$ emission was as large as the direct one for $80 \%$ reduction target. Moreover, for $95 \%$ reduction target, the indirect $\mathrm{CO}_{2}$ emission was three times larger than the direct one [27].

In the study of McDowall et al., the indirect emissions contributed to less than $10 \%$ of the total emissions of power sector in EU by 2050 [32], which was a small part, especially compared to the result of Blanco et al.'s study. It should be noted that while Blanco et al.'s study covered 18 economic sectors, the indirect emissions in McDowall et al.'s study includes that from energy equipment and construction [27, 32]. Besides, in spite of the small contribution of indirect emission of power sector in McDowall et al.'s study, the inclusion of these emissions into the optimization model of the power system made the renewable power less attractive and consequently, induced changes in the structure of the power sector [32].

The mismatch between direct and indirect environmental impacts of power sector was indicated by the cost of power generation. Algunaibet et al. quantified the life cycle indirect cost of electricity generation in the US and pointed out that other indirect environmental impacts of power sector need to be considered apart from direct GHG emissions. In the study, the costs of electricity were minimized with constraints on demand, generation potential and capacity factor, while achieving a particular target on emission. These costs included levelized cost of electricity (direct cost) and costs to endpoint life cycle indicators including human health, ecosystem diversity and resource availability (indirect cost, externalities) [34]. It was found that by meeting the emission reduction of Paris Agreement, the indirect costs of electricity generation could be reduced up to $63 \%$ [34]. In contrast, the withdrawal from Paris Agreement would cause to a cost up to $1103 \pm 206$ billion USD 2013 in BAU scenario by 2030 [34]. When both direct and indirect costs are optimized, the total cost for the energy system is $373 \pm 164$ billion USD 2013 in 2030 [34].

Elzein et al. assessed the GHG emission and operating cost of electricity generation of Normandy grid with the inclusion of energy storage system. The inclusion of energy storage system altered the generation of thermal and nuclear power plant, consequently, reduced the GHG emission by 53\%. At the same time, the operating cost reduced by $28 \%$ compared to the base case of historic power generation without energy storage system [37].

\section{CONCLUSION}

In this paper, it is argued that, by expansion of system boundary and inclusion of socio-economic interactions, CLCA shows its strength in quantifying indirect life cycle environmental impacts of power sector. Consequently, it is more suitable in analysing and assessing life cycle impacts of power sector compared to ALCA in the context of energy and environmental policy aiming at GHG emission reductions. It is indicated that there is a difference in the obtained results of reviewed CLCA papers on quantifying the indirect and total environmental impacts. The variation ranges widely from inconsiderable difference (less than $5 \%$ ) to $200 \%$, depending on the investigated product system. In most of the case, the GHG emission and other environmental impacts are larger with the application of CLCA, compared to ALCA. The variations in GHG emission quantifying results also impact the cost for GHG emission reduction in power system.
In term of methodology, the expansion of system boundary is observed in all reviewed papers by inclusion of unit processes, affected products and co-products, and economic sectors to the extent of changes. Although the affected products are treated differently among reviewed papers, it should be noted that the selected assumption, either ceteris paribus or mutatis mutandis, largely depends on the availability of data and the economic size of investigated product systems. With the expansion of system boundary, CLCA covers a larger number of affected products, and relevant unit processes, economic sectors. As a result, it would comprehensively quantify the environmental impacts which may be neglected in ALCA.

The inclusion of socio-economic indicators in a CLCA is frequently conducted by applying an economic modelling tool. The application of economic models and CLCA has the advantages of tracking the links between environmental impacts and socio-economic indicators, such as product demands or economic growth, domestic market or import/export market, and consumer behaviours. Therefore, CLCA would have an upgraded advantage of hotspot identification compared to ALCA.

\section{REFERENCES}

[1] UNFCCC. (2020). Annual greenhouse gas (GHG) emissions for Annex I, in $\mathrm{Gt}_{\mathrm{CO}_{2}}$ equivalent. Available: https://di.unfccc.int/comparison_by_category

[2] IEA. (2020). Energy Transitions Indicators. Available: https://www.iea.org/reports/energy-transitionsindicators

[3] Carnevale, P., Mattei, F.E.E. (2020). Roadmap to 2050: A Manual for Nations to Decarbonize by Mid-Century. Sustainable Development Solutions Network.

[4] Safonov, G. (2015). Pathways to deep carbonization 2015 report. Deep Decarbonization Pathways Project SDSN - IDDRI.

[5] Luu, L.Q., Halog, A. (2016). Rice husk based bioelectricity vs. Coal-fired electricity: Life cycle sustainability assessment case study in Vietnam. Procedia CIRP, 40: 73-78. https://doi.org/10.1016/j.procir.2016.01.058

[6] Horne, R.E. (2009). Life cycle assessment: origins, principles and context. In Horne RE, Grant $\mathrm{T}$ and Verghese K (eds) Life Cycle Assessment - Principles Practice and Prospects, CSIRO Publishing.

[7] Bjørn A, Owsianiak M, Molin C and Hauschild MZ. (2018). Chapter 3 LCA History. In: Hauschild MZ, Rosenbaum RK and Olsen SI (eds) Life Cycle Assessment, Springer International Publishing.

[8] Glasziou P. (2013). Chapter 14 How to write a review. In: Hall G (eds) How to write a paper, John Wiley and Sons Publishing.

[9] Ekvall T. (2002). Cleaner production tools: LCA and beyond. Journal of Cleaner Production, 5(10): 403-406

[10] Ekvall, T., Weidema, B.P. (2004). System boundaries and input data in consequential life cycle inventory analysis. International Journal on Life Cycle Assessment, 9(3): 161-171. https://doi.org/10.1007/BF02994190

[11] Curran, M.A., Mann, M., Norris, G. (2005). The international workshop on electricity data for life cycle inventories. Journal of Cleaner Production, 13(8): 853862. https://doi.org/10.1016/j.jclepro.2002.03.001 
[12] Soimakallio, S., Kiviluoma, J., Saikku, L. (2004). The complexity and challenges of determining GHG (greenhouse gas) emissions from grid electricity consumption and conservation in LCA (life cycle assessment): A methodological review. Energy, 36(12): 6705-6713.

https://doi.org/10.1016/j.energy.2011.10.028

[13] Earles, J.M., Halog, A. (2011). Consequential life cycle assessment: A review. International Journal of Life Cycle Assessment, 16(5): 445-453. https://doi.org/10.1007/s11367-011-0275-9

[14] Nielsen, P.H., Oxenboll, K.M., Wenzel, H. (2007). Cradel-to-gate environmental assessment of enzyme products produced industrially in Denmark by Novoaymes A/S. International Journal of Life Cycle Assessment, 12(6): 432-438 https://doi.org/10.1065/lca2006.08.265.1

[15] Roos, A., Ahlgren, S. (2018). Consequential life cycle assessment of bioenergy systems - A literature review. Journal of Cleaner Production, 189: 358-373. https://doi.org/10.1016/j.jclepro.2018.03.233

[16] Zamagni, A., Guinee, J., Heijungs, R., Masoni, P., Raggi, A. (2012). Lights and shadows in consequential LCA. International Journal of Life Cycle Assessment, 17(7): 904-918. https://doi.org/10.1007/s11367-012-0423-x

[17] Sanchez, S.T., Woods, J., Akhurst, M., Brander, M., O'Hare, M., Dawson, T.P., Malpas, R. (2012). Accounting for indirect land-use change in the life cycle assessment of biofuel supply chains. Journal of The Royal Society Interface, 9(71): 1105-1119. https://doi.org/10.1098/rsif.2011.0769

[18] Marvuglia, A., Benetto, E., Rege, S., Jury, C. (2013). Modelling approaches for consequential life-cycle assessment (C-LCA) of bioenergy: Critical review and proposed framework for biogas production. Renewable \& Sustainable Energy Reviews, 25: 768-781. https://doi.org/10.1016/j.rser.2013.04.031

[19] Weidema, B.P. (2003). Market information in life cycle assessment. Environmental Project no. 863. Danish Environmental Protection Agency, Copenhagen.

[20] Weidema, B.P., Frees, N., Nielsen, A.M. (1999). Marginal production technologies for life cycle inventories. International Journal of LCA, 4: 48-56. https://doi.org/10.1007/BF02979395

[21] Weidema, B.P., Ekvall, T., Heijungs, R. (2009). Guidelines for application of deepened and broadened LCA. Project no. 037075, Co-ordination Action for innovation in Life-Cycle Analysis for Sustainability CALCAS, The Italian National Agency on new Technologies, Energy and the Environment, ENEA.

[22] Frischknecht, R., Stucki, M. (2010). Scope-dependent modelling of electricity supply in life cycle assessments. International Journal of Life Cycle Assessment, 15(8): 806-816. https://doi.org/10.1007/s11367-010-0200-7

[23] Eriksson, O., Finnveden, G., Ekvall, T., Bjorklund, A. (2007). Life cycle assessment of fuels for district heating: A comparison of waste incineration, biomass- and natural gas combustion. Energy Policy, 35(2): 13461362. https://doi.org/10.1016/j.enpol.2006.04.005

[24] Pizarro-Alonso, A., Cimpan, C., Munnstr, M. (2018). The climate footprint of imports of combustible waste in systems with high shares of district heating and variable renewable energy. Waste Management, 79: 800-814. https://doi.org/10.1016/j.wasman.2018.07.006
[25] Moora, H., Lahtvee, V. (2009). Electricity scenarios for the Baltic states and marginal energy technology in life cycle assessments - A case study of energy production from municipal waste incineration. Oil Shale, 26: 331346. https://doi.org/10.3176/oil.2009.3S.14

[26] Pehnt, M., Oeser, M., Swider, D.J. (2008). Consequential environmental system analysis of expected offshore wind electricity production in Germany. Energy, 33(5): 747759. https://doi.org/10.1016/j.energy.2008.01.007

[27] Blanco, H., Codina, V., Laurent, A., Nijs, W., Marechal, F., Faaij, A. (2020). Life cycle assessment integration into energy system models: An application for Power-toMethane in the EU. Applied Energy, 259: 114160. https://doi.org/10.1016/j.apenergy.2019.114160

[28] Mathiesen, B.V., Munster, M., Fruergaard, T. (2009). Uncertainties related to the identification of the marginal energy technology in consequential life cycle assessments. Journal of Cleaner Production, 17(15): 1331-1338. https://doi.org/10.1016/j.jclepro.2009.04.009

[29] Lund, H., Mathiesen, B.V., Christensen, P., Schmidt, J.H (2010). Energy system analysis of marginal electricity supply in consequential LCA. International Journal of Life Cycle Assessment, 15(3): 260-271. https://doi.org/10.1007/s11367-010-0164-7

[30] Igos, E., Rugani, B., Rege, S., Benetto, E., Drouet, L., Zachary, D.S. (2015). Combination of equilibrium models and hybrid life cycle-input-output analysis to predict the environmental impacts of energy policy scenarios. Applied Energy, 145: 234-245. https://doi.org/10.1016/j.apenergy.2015.02.007

[31] Gibon, T., Hertwich, E.G., Arvesen, A., Singh, B., Verones, F. (2017). Health benefits, ecological threats of low-carbon electricity. Environmental Research Letters, 12(3): $\quad 034023 . \quad$ https://doi.org/10.1088/17489326/aa6047

[32] McDowall, W., Rodriguez, B.S., Usubiaga, A., Fernandez, J.A. (2018). Is the optimal decarbonization pathway influenced by indirect emissions? Incorporating indirect life-cycle carbon dioxide emissions into a European TIMES model. Journal of Cleaner Production, 170: https://doi.org/10.1016/j.jclepro.2017.09.132

260-268.

[33] Raugei, M., Leccisi, E., Azzopardi, B., Jones, C., Gilbert, P., Zhang, L., Mancarella, P. (2018). A multidisciplinary analysis of UK grid mix scenarios with large-scale PV deployment. Energy Policy, 114: 51-62. https://doi.org/10.1016/j.enpol.2017.11.062

[34] Algunaibet, I.M., Pozo, C., Galán-Martín, Á., GuillénGosálbez, G. (2019). Quantifying the cost of leaving the Paris Agreement via the integration of life cycle assessment, energy systems modeling and monetization. Applied Energy, 242: 588-601. https://doi.org/10.1016/j.apenergy.2019.03.081

[35] Vandepaer, L., Cloutier, J., Bauer, C., Amor, B. (2019). Integrating batteries in the future swiss electricity supply system: A consequential environmental assessment. Journal of Industrial Ecology, 23(3): 709-725. https://doi.org/10.1111/jiec. 12774

[36] Dandres, T., Gaudreault, C., Tirado-Seco, P., Samson, R. (2011). Assessing non-marginal variations with consequential LCA: Application to European energy sector. Renewable and Sustainable Energy Reviews, 
15(6):

$3121-3132$

https://doi.org/10.1016/j.rser.2011.04.004

[37] Elzein, H., Dandres, T., Levasseur, A., Samson, R. (2019). How can an optimized life cycle assessment method help evaluate the use phase of energy storage systems. Journal of Cleaner Production, 209: 1624-1636. https://doi.org/10.1016/j.jclepro.2018.11.076

[38] Jones, C., Gilbert, P., Raugei, M., Mander, S., Leccisi, E. (2017). An approach to prospective consequential life cycle assessment and net energy analysis of distributed electricity generation. Energy Policy, 100: 350-258. https://doi.org/10.1016/j.enpol.2016.08.030

[39] Choi, J.K., Friley, P., Alfstad, T. (2012). Implication of energy policy on a product system's dynamic life-cycle environmental impact: survey and model. Renewable and Sustainable Energy Reviews, 16(7): 4744-4752. https://doi.org/10.1016/j.rser.2012.05.032

[40] Jones, C., Gilbert, P. (2018). Determining the consequential life cycle greenhouse gas emissions of increased rooftop photovoltaic deployment. Journal of Cleaner Production, 184: 211-219. https://doi.org/10.1016/j.jclepro.2018.02.140

[41] Luu, L.Q., Longo, S., Cellura, M., Sanseverino, E.R., Cusenza, M.A., Franzitta, V. (2020). Conceptual review on using consequential life cycle assessment methodology for the energy sector. Energies, 13(12): 3076. https://doi.org/10.3390/en13123076

[42] Beaussier, T., Cairla, S., Maurel, V.B., Loiseau, E. (2019). Coupling economic models and environmental assessment methods to support regional policies: A critical review. Journal of Cleaner Production, 216: 408421. https://doi.org/10.1016/j.jclepro.2019.01.020

[43] Florent, Q., Enrico, B. (2015). Combining agent based modeling and life cycle assessment for the evaluation of mobility policies. Environmental Science and Technology, 49(3): 1744-1751. https://doi.org/10.1021/es5060868

[44] Onat, N.C., Kucukvar, M., Tatari, O. (2016). Uncertainty-embedded dynamic life cycle sustainability assessment framework: An ex-ante perspective on the impacts of alternative vehicle options. Energy, 112: 715728. https://doi.org/10.1016/j.energy.2016.06.129

[45] Hammond, G.P., O'Grady, A. (2017). The potential environmental consequences of shifts in UK energy policy that impact on electricity generation. Proceedings of the Institution of Mechanical Engineers Part a-Journal of Power and Energy, 231(6): 535-550. https://doi.org/10.1177/0957650916675519

[46] Frischknecht, R., Benetto, E., Dandres, T., Heijungs, R., Roux, C., Schrijvers, D., Tschuemperlin, L. (2017). LCA and decision making: when and how to use consequential LCA; 62nd LCA forum, Swiss Federal Institute of Technology, Zurich, 9 September 2016. International Journal of Life Cycle Assessment, 22(2): 296-301. https://doi.org/10.1007/s11367-016-1248-9

\section{NOMENCLATURE}

$\mathrm{gCO}_{2} \quad$ Gram carbon dioxide

$\mathrm{GtCO}_{2} \mathrm{e} \quad$ Giga ton of carbon dioxide equivalent

ha Hectare

kWh Kilo watt hour

$\mathrm{tCO}_{2} \mathrm{e} \quad$ Ton of carbon dioxide equivalent

tPe Ton of phosphorus equivalent

USD US dollar 